\title{
The Characteristics of Spatial and Temporal Variations in the PBL during the Landfall of Tropical Cyclones across East China
}

\author{
YONG HAN ${ }^{\mathrm{a}}$ \\ Guangdong Province Key Laboratory for Climate Change and Natural Disaster Studies, School of Atmospheric \\ Sciences, Sun Yat-Sen University, Guangzhou, and School of Atmospheric Sciences, Nanjing University, \\ Nanjing, and Southern Laboratory of Ocean Science and Engineering, Guangdong, Zhuhai, China \\ YIWEN ZHOU ${ }^{\mathrm{a}}$ \\ School of Atmospheric Sciences, Nanjing University, Nanjing, China \\ JIANPING GUO \\ State Key Laboratory of Severe Weather, and Key Laboratory of Atmospheric Chemistry of the China \\ Meteorology Administration, Chinese Academy of Meteorological Sciences, Beijing, China \\ YONGHUA WU \\ NOAA/Center for Earth System Sciences and Remote Sensing Technologies (CREST), City College of the City \\ University of New York, New York, New York \\ Tijian Wang, Bingliang Zhuang, And Mengmeng Li \\ School of Atmospheric Sciences, Nanjing University, Nanjing, China
}

(Manuscript received 9 May 2018, in final form 3 May 2019)

\begin{abstract}
The planetary boundary layer (PBL) controls the exchange of momentum and energy between the ground surface and the free troposphere, but few studies have been involved in the connection of the PBL with the development and extinction of tropical cyclones (TCs). Studies on the PBL usually need high-resolution soundings in the lowest troposphere that are otherwise quite rare with traditional technology. Here, 1-s resolution L-band radiosonde data are acquired to study the variations in PBL characteristics associated with the development of TCs in eastern China. The strong variations in the vertical profiles of temperature, relative humidity, and wind speed in the PBL during the landfall of a TC are revealed. In addition, four typical methods, including the virtual potential temperature method, Holzworth method, bulk Richardson number method, and potential temperature gradient method, are applied to estimate the PBL height (PBLH). The results indicate that the PBLHs derived by these methods vary by several hundred meters, which may be related to their different definitions of kinetic or thermodynamic theories. Furthermore, the PBLH was found to display a slight upward tendency during the landfall of TC.
\end{abstract}

\section{Introduction}

The planetary boundary layer (PBL), which is the lowest level of the atmosphere, is directly influenced by

\footnotetext{
${ }^{\text {a }}$ Yong Han and Yiwen Zhou are co-first authors with equal contributions.
}

Corresponding author: Yong Han, hany66@mail.sysu.edu.cn. the exchange of momentum, heat, and water vapor near Earth's surface. The time scale for atmospheric turbulence is approximately an hour or less within the PBL, which dominates the horizontal and vertical transport of atmospheric components (Stull 1988; Powell 1990; Kaimal and Finnigan 1995; Li et al. 2017). As a crucial part of the places where a mature tropical cyclone (TC) mainly occurs, the PBL and its characteristics are closely related to the vertical distribution and transport of 
temperature, moisture, pressure, and wind (Shapiro 1983; Vickery et al. 2009; Cai et al. 2014), which affects the development, intensification and extinction of storms (Wang and Wu 2004, Rao and Prasad 2007; Smith and Vogl 2008; Williams et al. 2013). Under the influence of large-scale tropical cyclone cloud systems, the lack of valid vertical atmospheric observation data often forces us to resort to parameterization schemes to study the characteristics of the PBL (Braun and Tao 2000; Hu et al. 2010). Among the various macrophysical processes, the PBL of a TC plays a significant role in the upward transfer of energy acquired from an ocean or land source.

A large number of pioneering studies indicate that the PBL regulates the dynamic and thermal dynamic processes in a mature TC, such as radial distribution of heat (Rayhun et al. 2015), moisture (Tang and Tan 2007), and angular momentum (Shapiro1983). During the landfall of TC, Williams (2015) discovered the asymmetric PBL wind structure, and the structure variation of the TC PBL was complex and almost unmeasurable. Both observation and simulation studies (Tuleya 1994) have implicated the loss of evaporation as the primary mechanism that causes a TC to decay over land. In addition, the studies also identified a discontinuity in the wind at the coast due to increased roughness. Howard et al. (2004) used surface stations to identify an inverse relationship between wind speed and distance from the coast. Kepert (2002) analyzed 30 dropsondes released in Hurricane Mitch (1998) and found that Mitch displayed large asymmetries in the near eyewall region because of the proximity of land (Schneider and Barnes 2005). Powell (1987) found asymmetries in the surface wind field of Hurricane Alicia (1983) during landfall in the Galveston area. Studies of Hurricane Danny by Blackwell (2000) revealed precipitation and wind maxima in the offshore flow much like that seen in Alicia (1983). The proximity of a large landmass generally increases the likelihood that the TC develops more asymmetric kinematic and thermodynamic fields (Wu and Kuo 1999). Chen et al. (2004) showed that the thickness of boundary layer of target typhoon Vongfong (2014) was strongly increased when it made landfall and this is became calmed down one day after Vongfong made landfall. Most of tropical cyclones approaching the mainland would decrease its intensity aside from few typhoons aside from a few typhoons that could increase its intensity if some mesoscale vortex (MSV) merged into it. After carrying out the numerical simulation of with and without the emergence of MSV, Chen et al. (2004) exhibit that the MSV merged into a typhoon plays an important role for the great decrease of central pressure and intensifies the typhoon.

At present, the properties of a TC PBL still cannot be fully resolved via subgrid-scale parameterization schemes alone in numerical simulation, even though they are high-resolution models (Sateesh et al. 2017). Therefore, it is of importance to understand how surface fluxes, vertical mixing, and horizontal advection vary within the PBL by altering numerical simulations. As such, we can understand the limitations of current assumptions. Therefore, a better understanding of the PBL structure has become increasingly imperative and urgent in an effort toward better PBL parameterization schemes.

To quantify the characteristics of the PBL, one of the most fundamental variables is the planetary boundary layer height (PBLH), which is commonly used as an important indicator in weather, climate, and air-quality models. Previous studies have clearly illustrated that the PBLH varies largely in time and space (Seidel et al. 2010; Guo et al. 2016; W. Zhang et al. 2016, 2018). During a diurnal cycle, the PBLH is usually shallow at midnight because of strong nocturnal thermodynamic stability near the surface. Then, it begins to develop into the convective boundary layer in the morning, reaches several kilometers in the afternoon, and persists until sunset, with a range that changes from several hundred meters to one or two kilometers (Stull 1988; Guo et al. 2016). Traditionally, the PBLH can be determined from different instruments, such as satellites (Leventidou et al. 2013), sodars (Casasanta et al. 2014), and groundbased lidar ( $\mathrm{Pal}$ 2014). In past decades, radiosonde data have been one of the most common data sources because of their wide station distribution and easy accessibility around the world. Most of early studies on the PBLH adopted the thermodynamic definition method, where momentum fluxes with potential temperature tended to be near zero at the top of the boundary layer (Moss and Merceret1976). In numerical models, the bulk Richardson number method (BRNM) has been extensively used because of its reliability for all atmospheric conditions (Anderson 2009). Based on the vertical profiles of temperature, humidity, and wind speed, Seidel et al. (2010) used seven methods to compute and compare PBLHs from a 10-yr radiosonde datasets of 505 stations and showed that various methods could lead to uncertainties of several hundred meters. However, direct measurements within the PBL of a TC are scarce. Despite emphasizing the importance of determining the PBLH, there is still no agreement on PBLH estimates of a TC. Typically, different methods usually reveal different aspects of PBL characteristics, which lead to PBLH differences. Although previous studies have suggested that the thermodynamic PBL is mixed by heating from the surface below, which is often identical to the boundary layer (Kepert et al. 2016). Understanding the different aspect of PBLH, especially the PBLH of a TC, is critical not only to the investigation of 
atmospheric structures and energy transmissions, but also to the accurate forecasting of potential intensities and risk reductions in severe weather. Therefore, understanding the PBLH, especially the PBLH of a TC, is critical not only to the investigation of atmospheric structures and energy transmissions, but also to the accurate forecasting of potential intensities and risk reductions in severe weather.

The PBLH has an enormous influence on the distribution and concentration of aerosols and the transport of water and air pollution between the surface and free atmosphere (Seibert et al. 2000; Davies et al. 2007; Barlow 2014). Although there are many works that have been conducted on the structure and intensity of TCs, studies on the TC PBL are still insufficient. One of the primary reasons is that the TC PBL is completely distinct from the ordinary atmospheric PBL because of the strong effect of the TC rotation on its dynamics (Eliassen and Lystad 1977). Another reason is that observations near the center of TCs are rare, which leads to TC PBLs receiving less attention than other aspects of TCs. Previous radiosonde measurements in China before 2007 , which only provided a few records below $500 \mathrm{hPa}$ at 0000 and $1200 \mathrm{UTC}$, had insufficient vertical and temporal resolutions for PBLH estimates within an acceptable level of uncertainty (Y. Zhang et al. 2018). Moreover, the determination of the PBLH still has incomplete agreement when different methods are used.

Therefore, the aim of this study is to exploit the unique PBL characteristics and PBLH using relatively high-temporal-resolution (1 s) radiosonde datasets. We first study the effect of the landfall of TC Chan-hom on the variations in the temperature, moisture, and wind field at four radiosonde stations (the Nanjing, Hangzhou, Shanghai, and Hongjia stations) along the east coast area of China. The atmospheric structure differences during, before and after TC landfall are also compared. To study the specific PBLH characteristics, four different methods, including the virtual potential temperature method (VPTM), Holzworth method (HM), BRNM, and potential temperature gradient method (PTGM) will be used to determine the PBLH. These methods generally yield height estimations that differ by several hundred meters. In addition, another five TCs (Meari, Damrey, Hai-kui, Matmo, and Fung-wong) are analyzed to gain a better understanding of the average PBLH during TC landfall.

The rest of this paper proceeds as follows. In section 2, a description of the methodology used to calculate the PBLH, a brief introduction of the six TCs and the dataset used are given. Section 3 presents and discusses the observational results of the characteristics of the PBL flux variations. The comparison results of the PBLHs calculated using four different methods to obtain the average PBLH of six TCs are also presented. In addition, a short summary is shown in section 4 .

\section{Dataset and methods}

\section{a. Description of the dataset}

To obtain flux variations in the PBL, data from the L-band sounding system via the China Meteorological Administration (CMA) were selected. Detailed profiles of the atmosphere at a 1-s resolution twice a day (0000 and 1200 UTC) are provided, including pressure, temperature, relative humidity, wind speed, and wind direction.

The characteristics of the PBL often vary with dynamic and thermodynamic processes in the atmosphere, particularly during the time period of landfall or the overpass of a TC. To understand the temporal variations in the PBL, an 8-day period has been selected for each TC, including the day when the TC made landfall, three days before landfall and four days after landfall. For example, sounding data for TC Chan-hom are collected for the period 8-15 July 2015. Four radiosonde stations (Nanjing, Shanghai, Hangzhou, and Hongjia) were influenced by the TC cloud rainband along the east coast of China. Figure 1 shows the locations of the four aforementioned radiosonde stations, along with the track of Chan-hom, from 0600 UTC 29 June to 0000 UTC 13 July 2015. The landfall times, locations, and time periods for each TC were also presented. For the convenience of research, we define the time when the TC eye is located closest to Nanjing as the fourth day in the following analyses.

To examine the tropical cyclone boundary layer (TCBL) thermal structure, a dataset of the Atmospheric Infrared Sounder (AIRS) was also used. AIRS was launched into Earth orbit on the NASA Aqua mission on 4 May 2002. It represents a breakthrough in infrared space instrumentation and has 2378 infrared channels in the range of $3.7-15.4 \mu \mathrm{m}$ with a nominal spectral resolution of 1200 . This high frequency of hyperspectral soundings has been heralded as important in the study of both severe weather prediction and climate monitoring (Chahine et al. 2006). The temperature and water vapor profile from the AIRS instrument on 10,11, and 12 July 2015 at the landing point of TC Chan-hom are discussed in section 3c.

\section{b. PBLH estimation}

This work applies several methods to determine the PBLH, with radiosonde data with a 1-s temporal resolution, and intercomparison analyses are performed. First, the HM is widely used for the detection of PBLHs, 


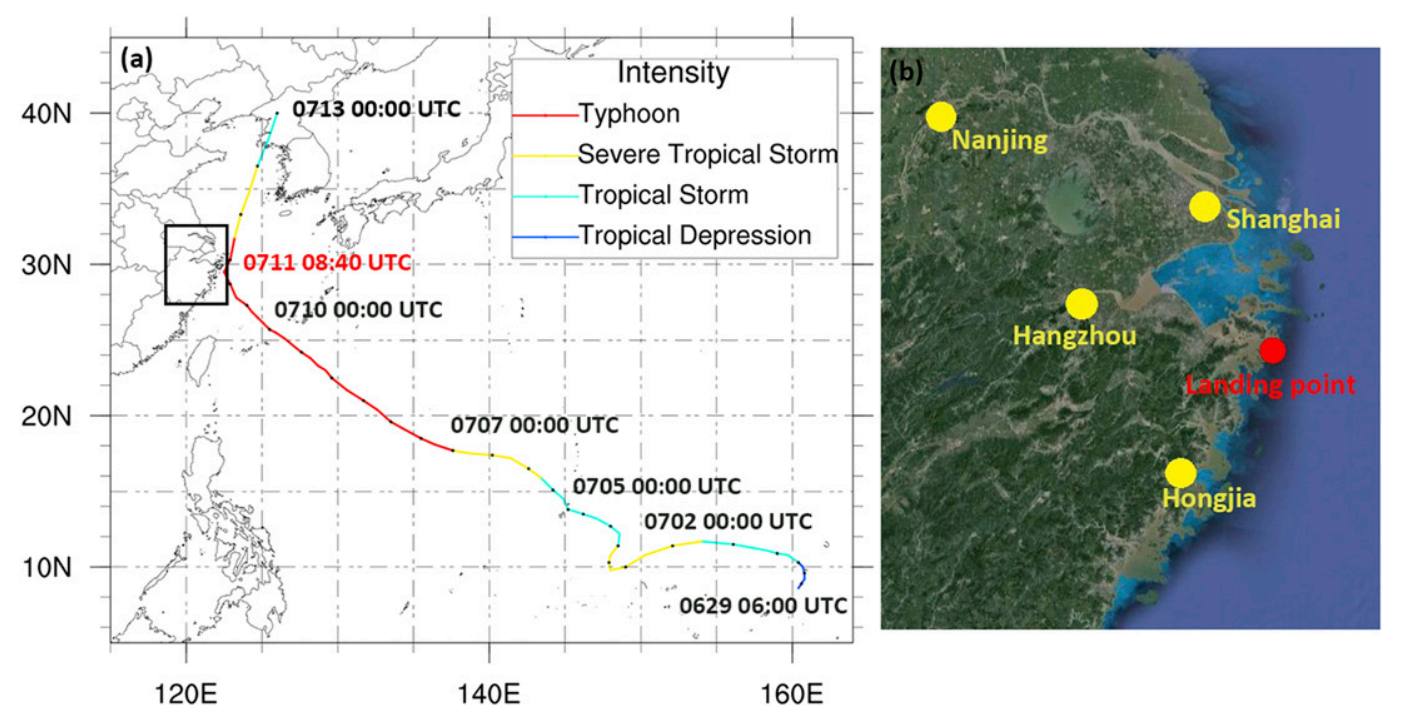

FIG. 1. (a) The ground track derived from the Japan Meteorological Agency (JMA) for TC Chan-homand. (b) The spatial distribution of the radiosonde stations at Nanjing, Shanghai, Hangzhou, and Hongjia (yellow dots) and the landfall point of Chan-hom (red dot).

which takes advantage of radiosonde data. This layer, which is adjacent to the ground, typically displays considerable variation in its temperature structure and depth. It is commonly used to characterize the vertical extent of mixing within the PBL. The HM assumes that advection, descending motion, mechanical turbulence, and other microscale effects are relatively small in comparison to the contribution from diurnal temperature differences (Holzworth 1964). And the HM method is probably not reliable for the TCs in the open ocean because of the strong advection. The thermodynamic effects from the ocean surface were also smaller compared to the dynamic effect. One can identify a height where a parcel of dry air is released adiabatically from the surface and reaches equilibrium with its environment. The PBLH is determined from the intersection between the dry adiabatic curve (starting from the maximum surface temperature collected from the meteorological station) and the temperature profiles, which is measured by a microwave radiometer (GranadosMunoz et al. 2012). The second common method is the VPTM, which determines the height where the virtual potential temperature increases by $0.5 \mathrm{~K}$ from its mean value in the lowest $150 \mathrm{~m}$ (Anthes and Chang 1978; Ming et al. 2014)

A traditional approach to estimate the PBLH in numerical weather simulations is to use a threshold value for the bulk Richardson number $\mathrm{Ri}_{b}$ throughout the whole PBL (Hanna 1969; Vogelezang and Holtslag 1996). For many years, this approach has been widely used to determine the PBLH in parameterization schemes and observation studies (Noh et al. 2003;
Bender et al. 2007; Shin and Hong 2011). The $\mathrm{Ri}_{b}$ is commonly defined as

$$
\mathrm{Ri}_{b}=\frac{g / \theta_{v 0}\left(\theta_{v z}-\theta_{v 0}\right)}{u_{z}^{2}+v_{z}^{2}}
$$

where $g$ represents the acceleration of gravity; $z$ represents the height above the ground; $\theta_{v z}$ and $\theta_{v 0}$ represent the virtual potential temperature at $z$ and the ground surface, respectively; $u_{z}$ and $v_{z}$ are the horizontal and vertical components of the wind at $z$, respectively. The BRNM defines that the PBLH is the height where the $\mathrm{Ri}_{b}$ reaches a threshold value $\left(\mathrm{Ri}_{b c}\right)$.

The PTGM adopts the level of the maximum vertical gradient for potential temperature $(\Theta)$ as the PBLH (Sorbjan 1989; Oke 2002; Nieuwstadt 2005), which is indicative of a transition from a convective region to a more stable region. Because of the lack of continuous potential temperature data, we substitute the central difference $\left(\theta_{n+1}-\theta_{n-1}\right) / \Delta Z$ for $\partial \theta / \partial Z$ in this study. To avoid invalid data, the results are discarded if the PBLH is found to be greater than $3000 \mathrm{~m}$ by all of these methods.

\section{c. Introduction of six TCs}

Six TCs, including Meari, Damrey, Hai-kui, Matmo, Fung-wong, and Chan-hom (Fig. 2), are selected to explore the characteristic variations in the PBL during their landfalls. All of these TCs have the closest distance to Nanjing when the TC is in the developing stage. The closest distances from the typhoon eyes of the six TCs to Nanjing are $554.591 \mathrm{~km}$ for Meari, $303.88 \mathrm{~km}$ for 


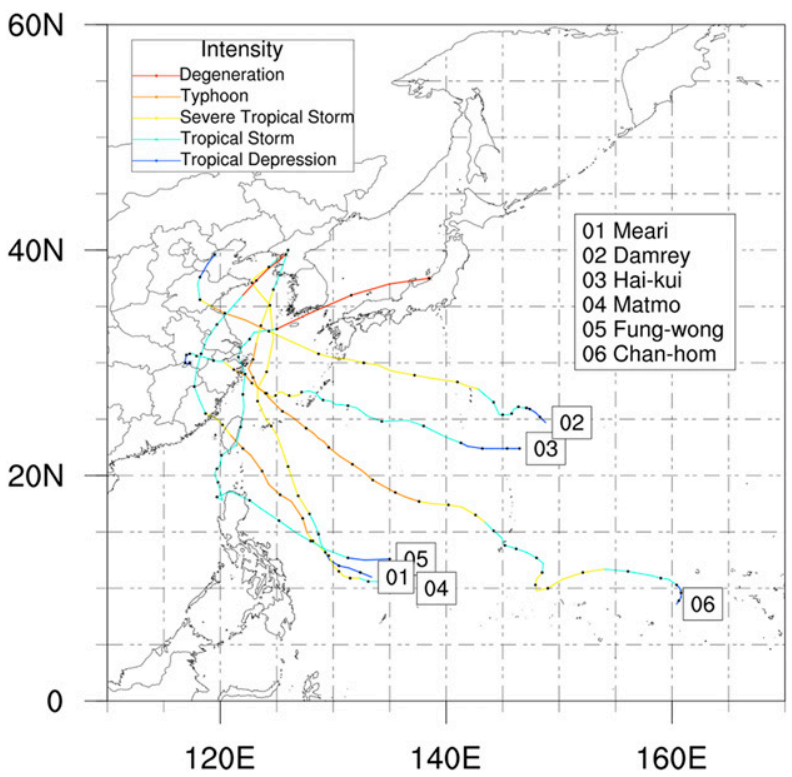

FIG. 2. The tracks of the six TCs (i.e., Meari, Damrey, Hai-kui, Matmo, Fung-wong, and Chan-hom) that had great impacts on the Nanjing station from 2012 to 2015.

Damrey, $175.50 \mathrm{~km}$ for Hai-Kui, $11.50 \mathrm{~km}$ for Matmo, $298.79 \mathrm{~km}$ for Fung-wong, and $415.46 \mathrm{~km}$ for Chan-hom. Detailed information about the stations is shown in Table 1. Other information on the 6 TCs is shown in Table 2.

The JMA issued the ground track for Chan-hom from 0600 UTC 29 June to 0000 UTC 13 July. All of the data include 6-hourly estimates $(0000,0600,1200$, and 1800 UTC) of the TC location, the wind radius, and TC intensity. During TC landfall, intensive observations are conducted every three hours (e.g., 0000, 0300, 0600, 0900, 1200, 1500, 1800, and 2100 UTC).

TC Chan-hom developed from a westerly wind burst in late June in the Southern Hemisphere. At 0600 UTC 29 June 2015, the JMA classified it as a tropical depression that moved steadily to the west. The system turned to the northeast on 3 July 2015. Later that day, the broad circulation veered northwest. On 7 July 2015, Chan-hom hit the Philippines. Later, on 9 July 2015, the typhoon passed through the islands of Okinawa and Miyako-jimain Japan, and Chan-hom reached its peak intensity, with maximum sustained winds of $165 \mathrm{~km} \mathrm{~h}^{-1}$ and a barometric pressure of $935 \mathrm{hPa}$ according to the JMA; it gradually weakened before landing in Zhoushan (Zhejiang Province) $\left(29.53^{\circ} \mathrm{N}, 122.14^{\circ} \mathrm{E}\right)$ at approximately 0840 UTC 11 July 2015. After landfall, Chan-hom was expected to turn northeast moving over the Yellow Sea, and it dissipated after moving over the Korean Peninsula (Liang et al. 2016; Xu et al. 2016). Chan-hom was a large, powerful, and long-lived tropical
TABLE 1. The IDs, locations (lat and lon), and altitudes of the Nanjing, Shanghai, Hangzhou, and Hongjia stations across East China

\begin{tabular}{lcccc}
\hline \multicolumn{1}{c}{ Station } & Nanjing & Shanghai & Hangzhou & Hongjia \\
\hline ID & 58238 & 58362 & 58457 & 58665 \\
Location & $32.00^{\circ} \mathrm{N}$, & $31.40^{\circ} \mathrm{N}$, & $30.23^{\circ} \mathrm{N}$, & $28.37^{\circ} \mathrm{N}$, \\
& $118.80^{\circ} \mathrm{E}$ & $121.45^{\circ} \mathrm{E}$ & $120.17^{\circ} \mathrm{E}$ & $121.25^{\circ} \mathrm{E}$ \\
Altitude $(\mathrm{m})$ & 7.1 & 5.5 & 41.7 & 5 \\
\hline
\end{tabular}

cyclone that affected most cities along the east coast areas of China. Throughout Zhejiang, Chan-hom ruined 700 houses. In the neighboring Jiangsu Province, there were approximately 300 houses that were damaged and destroyed, causing 120 million yuan in economic losses.

\section{Results}

\section{a. Variations in PBL flux}

As we discussed above, the PBLH is usually less than a height of $2 \mathrm{~km}$. Therefore, in order to discover the temporal and spatial variations in the PBL, all fluxes, including temperature, relative humidity, and wind speed, under $5000 \mathrm{~m}$ are discussed in this paper. Figure 1a shows that TC Chan-hom affected the Hongjia, Hangzhou, Shanghai, and Nanjing stations at 0000 UTC 11 July 2015. In addition, the Shanghai station was closer to the center of the TC, and the variation characteristics of the PBL there were more significant than those at the Nanjing station.

As shown in Fig. 3, before the landfall of Chan-hom, no extremely high temperatures were observed at low levels at the four stations. Above $2000 \mathrm{~m}$, the temperature was lower than $288 \mathrm{~K}$ and continually decreased with increasing height (see Figs. 3a,d,g,j). On 8 and 9 July 2015, the temperature slowly reached $295 \mathrm{~K}$ under a height of $500 \mathrm{~m}$. The Chan-hom resulted in a sharp decrease in surface temperature throughout the four stations, with the most significant changes occurring in the height ranges of 0 to $2000 \mathrm{~m}$. With the landfall of the TC, the atmospheric temperature of this layer decreased approximately $3-4 \mathrm{~K}$ on 11 July at the Hangzhou, Nanjing, and Shanghai stations. This phenomenon occurred sooner (10 July 2015) at the Hongjia station. After 12 July 2015, the extremely hot weather led to temperatures that increased quickly. Near the surface, several appeared, and the temperature throughout the whole layer temperature had increased.

The temporal variations in relative humidity (Figs. 3b,e,h,k) showed that the TC landfall brought plenty of moisture into the lower atmosphere from the ocean toward inland regions. Although thunderstorms could have affected the distribution of moisture for a 
TABLE 2. The landfall times, locations, and time periods for each TC: Meari, Damrey, Hai-kui, Matmo, Fung-wong, and Chan-hom.

\begin{tabular}{llcc}
\hline \hline \multicolumn{1}{c}{ TC } & Duration & $\begin{array}{c}\text { The date with nearest } \\
\text { distance to Nanjing }\end{array}$ & Research scope \\
\hline Meari & 20-27 Jun & $25 \mathrm{Jun}$ & Year \\
Damrey & 27 Jul-4 Aug & 2 Aug & 2011 \\
Hai-kui & 1-11 Aug & 9 Aug & 30 Jul-6 Aug \\
Matmo & 16-26 Jul & $24 \mathrm{Jul}$ & $6-13$ Aug \\
Fung-wong & 17-25 Sep & $23 \mathrm{Sep}$ & $21-28 \mathrm{Jul}$ \\
Chan-hom & 29 Jun-13 Jul & $11 \mathrm{Jul}$ & $20-27 \mathrm{Sep}$ \\
\hline
\end{tabular}

short time period before 11 July, the relative humidity decreased sharply at $2000 \mathrm{~m}$ at the Nanjing, Shanghai and Hangzhou stations. At the Hongjia station, the decrease was not so obvious, but it also dropped from $90 \%$ to $70 \%$ between 1000 and $3000 \mathrm{~m}$. Compared to the days after 12 July, we discovered that the relative humidity could reach up to $90 \%$ when influenced by Chan-hom from the surface to $5000 \mathrm{~m}$. However, with increased of time and temperature, the relative humidity gradually declined and became lower than $30 \%$ above $3000 \mathrm{~m}$ in some places. The high ambient humidity appeared only under $1000 \mathrm{~m}$ near the surface.

In contrast with temperature $(\mathrm{K})$, the relative humidity and wind speed exhibited more obvious variations (Figs. 3c,f,i,l). Nanjing station was less affected among the 4 stations since it is furthest from the TC center. Late on 10 July 2015, the wind in Nanjing increased quickly above $500 \mathrm{~m}$, and the maximum wind velocity reached up to $25 \mathrm{~m} \mathrm{~s}^{-1}$. However, at the Shanghai and Hangzhou stations, the velocity at this height surpassed $30 \mathrm{~m} \mathrm{~s}^{-1}$. Hongjia station was most affected by the TC, with winds that maintained persistent high speeds $\left(30 \mathrm{~m} \mathrm{~s}^{-1}\right)$ on 10 and 11 July 2015.

For the meteorological element profiles of multiple TCs, Fig. 4 illustrates the average states of the temperature, relative humidity, and wind speed profiles. By comparing them to a single case of a TC, the average state eliminated the effect of other weather process and some instability problems. To facilitate the comparison, we chose " 0 " on the $x$ axis as the day with the nearest distance to Nanjing for the 6 TCs. The temperature profiles showed smooth changes on that day. In all levels between 0 and $5000 \mathrm{~m}$, the temperature slightly decreased by $2-3 \mathrm{~K}$ and soon increased during the next day. Two days after the TCs had passed, the temperatures became closer to those before the TC. The relative humidity above $2000 \mathrm{~m}$ before landfall was less than $50 \%$, and it dropped to $20 \%$ near $5000 \mathrm{~m}$. The TCs brought a vast quantity of water vapor from the deep ocean. Therefore, the relative humidity in the PBL increased to $90 \%$ between 0 and $2000 \mathrm{~m}$ and to $70 \%$ above $2000 \mathrm{~m}$ on that day. The characteristics of the low-level wind during this time period were also very obvious. In this study, we focus on the PBLH estimate, and we would like to investigate such influences on the wind fields in details for the different storms or TCs in the next study. The speed improved greatly one day before TC landfall, and the high-speed winds lasted one and half days. The average speed was $15 \mathrm{~m} \mathrm{~s}^{-1}$, which was much lower than the speed of a single TC. In summary, the variability in the three parameters for the $6 \mathrm{com}$ bined TCs were not as obvious as those for a single TC, but the main variation features are all presented in Fig. 4.

\section{b. PBLH estimation}

The PBLH of a TC is closely related to the distance to the TC eye. We first calculated the distances between the TC centers and the four stations. Based on the best track data from the JMA, Fig. 5a shows that the shortest distances for each station were $165.15 \mathrm{~km}$ from Hongjia at $0000 \mathrm{UTC}, 237.57 \mathrm{~km}$ from Hangzhou at $0600 \mathrm{UTC}$, $171.55 \mathrm{~km}$ away from Shanghai at 1200 UTC, and $414.58 \mathrm{~km}$ from Nanjing at 1800 UTC on 10 July 2015.

Kepert (2001) confirmed that the inward advection of angular momentum produces a boundary layer jet and this boundary layer jet is maintained primarily by vertical advection. In addition, a linear analytical model suggested that the jet height could be defined by $(2 K / I)^{1 / 2}$, where $K$ represents the turbulent diffusivity and $I$ represents the inertial stability (Kepert 2001). Therefore, the shorter the distance to the core of a TC is, the lower the PBLH. The PBLH is typically several hundreds of meters inside of the cyclone core and increases as the radius of the TC increases.

The PBLH calculated by this method was closely related to the distance in Fig. 5b. Although the PBLH at the Hongjia station on 10 July was missing, the height results matched well with the linear analytical model. On one hand, the PBLH calculated by the HM is shallower than the height calculated by the BRNM. On the other hand, the linear model verified that the closer distance to the TC center, the lower PBLH it will be. The change trend of PBLH in Fig. 5b is in contrast with the result by the other method. On the date of landfall, the PBLH in Shanghai and Hangzhou is higher than that 

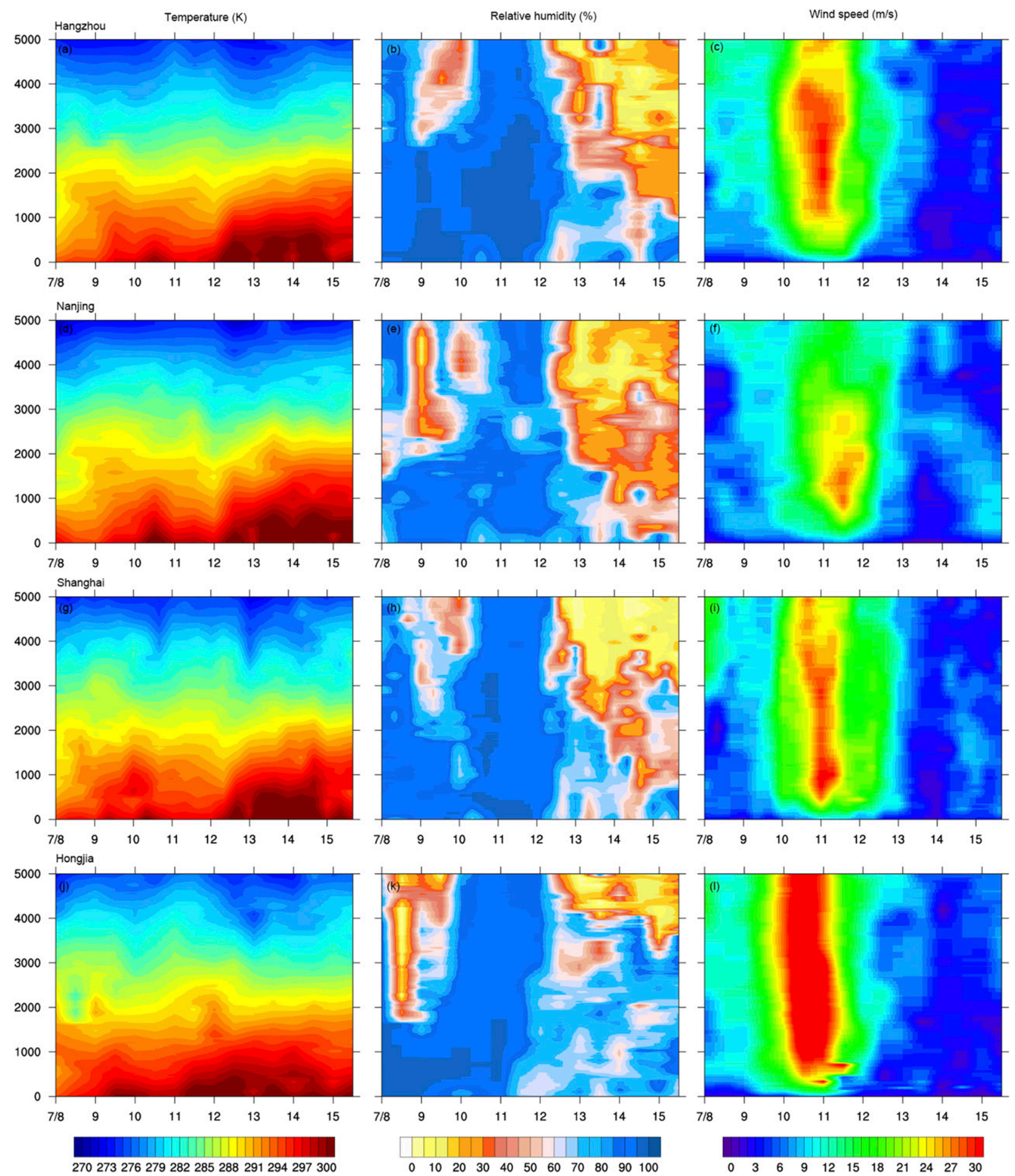

FIG. 3. The profiles of temperature (K), relative humidity (\%), and wind speed $\left(\mathrm{m} \mathrm{s}^{-1}\right)$ at the (a)-(c) Hangzhou (d)-(f) Nanjing, (g)-(i) Shanghai, and (j)-(l) Hongjia stations from 8 Jul to $15 \mathrm{Jul} 2015$. The horizontal axis represents the time, and the vertical axis represents the height (m).

in Nanjing and Hongjia station. We will emphasize the conclusion again in this part. The general trends at the four stations showed that the PBLH always decreased to lower than $800 \mathrm{~m}$ under the influence of a TC and then increased significantly with the increase in temperature. With the movement of Chan-hom, the farthest station (Nanjing) had the highest PBLH $(701.98 \mathrm{~m})$, and the Shanghai station had the lowest PBLH $(282.64 \mathrm{~m})$ of 

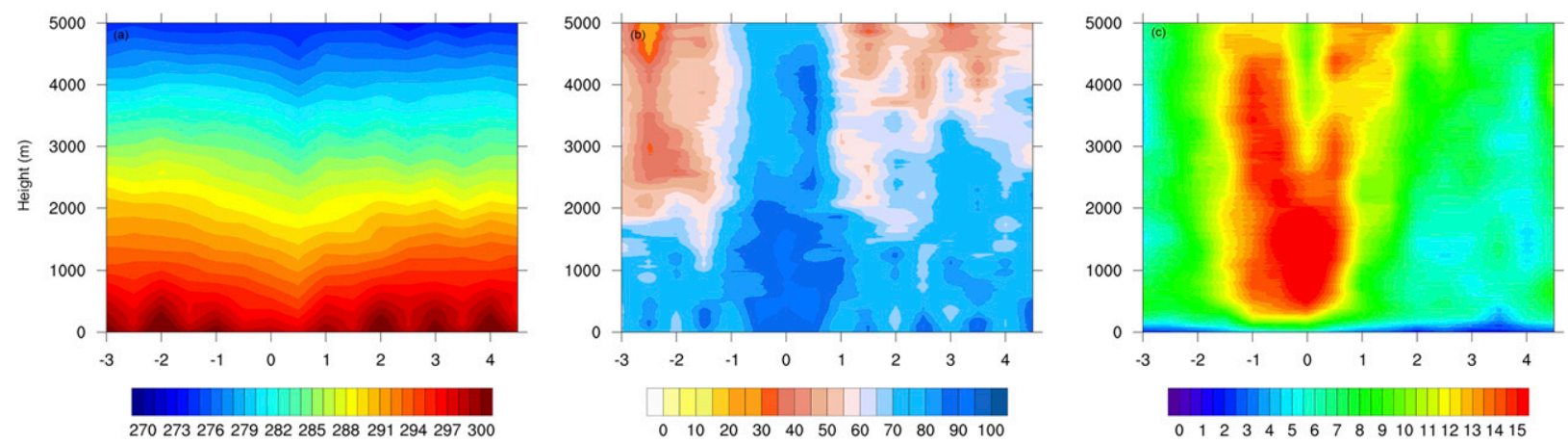

FIG. 4. The average profiles of (a) temperature (K), (b) relative humidity (\%), and (c) wind speed ( $\mathrm{m} \mathrm{s}^{-1}$ ) at the Nanjing station during the landfalls of six TCs. The $y$ axis represents the detection height, and the $x$ axis represents the temporal deviation between the detected and nearest distances to the Nanjing station.

the four stations. For the Hangzhou station, the height was $473.33 \mathrm{~m}$ on 11 July. Because the Hongjia station was influenced by Chan-hom early on 10 July, the PBLH was $76.72 \mathrm{~m}$, and it was much lower than those of the other three stations. The maximum of PBLHs from 12 to 14 July were $1897.51,1798.30,1282.71$, and $1244.75 \mathrm{~m}$ at the Hangzhou, Nanjing, Shanghai, and Hongjia stations, respectively. This indicated that the increase in temperature near the surface could adequately mix up the atmosphere at low levels, thereby increasing the PBLH during this period. By comparing the distance and the PBLH, we discovered that the results produced by the HM indicated that there were more emphasis on the influence on surface temperature and vertical transport. In addition, the height produced by this method did not violate the theory (Kepert 2001) that the PBLH decreases with the increase in distance from the TC eye.

By utilizing the VPTM, the PBLH can be calculated twice a day at 0000 and 1200 UTC (Fig. 6). The results produced by the VPTM showed a shallower height compared to the other methods from 8 to $15 \mathrm{July}$. At the same time, the diurnal cycle characteristics of the PBLH became dramatic with the height fluctuations every day. The PBLHs at the Nanjing station were mostly below $600 \mathrm{~m}$, except at 0600 UTC 10 July. At 0600 UTC [1400 Beijing time (BJT)] 10 and 11 July, the temperature reached a peak during a day, which may have enhanced the thermodynamic process of the boundary layer. At 0600 UTC 11 July, two hours before the TC landed, the PBL heights were $382,668,224$, and $810 \mathrm{~m}$ at the Hangzhou, Nanjing, Shanghai, and Hongjia stations, respectively. When the temperature was recovered on 13 July, the PBLHs at these stations decreased by at least $200 \mathrm{~m}$.

When calculating the PBLH via the BRNM, a $\mathrm{Ri}_{b c}$ should be confirmed properly. Previous research has suggested that the value of $\mathrm{Ri}_{b c}$ usually varies from 0.15 to 1.0 (Flamant et al. 1997; Zilitinkevich and Baklanov 2002; Dai et al. 2014) according to different boundary layer conditions, such as strongly stable boundary layers,
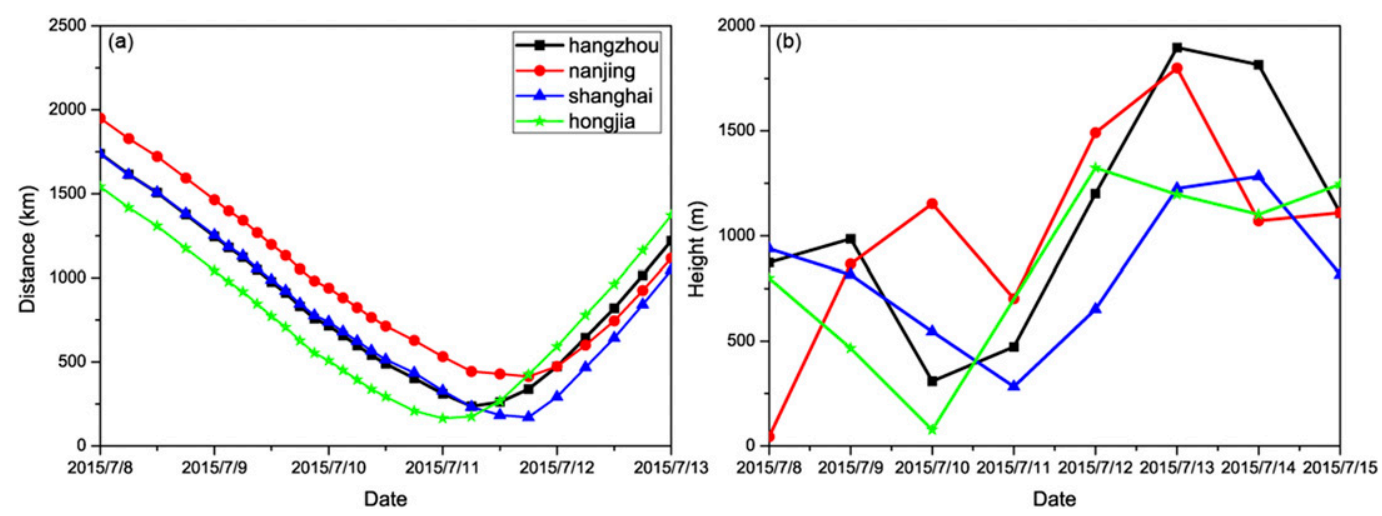

FIG. 5. (a) The temporal variations in distance from the TC eye to the Nanjing, Shanghai, Hangzhou, and Hongjia stations from $8 \mathrm{Jul}$ to $13 \mathrm{Jul} 2015$, and (b) their corresponding PBLHs calculated from radiosonde measurements at 0000 UTC from 8 Jul to 15 Jul 2015, using the Holzworth method (HM). 


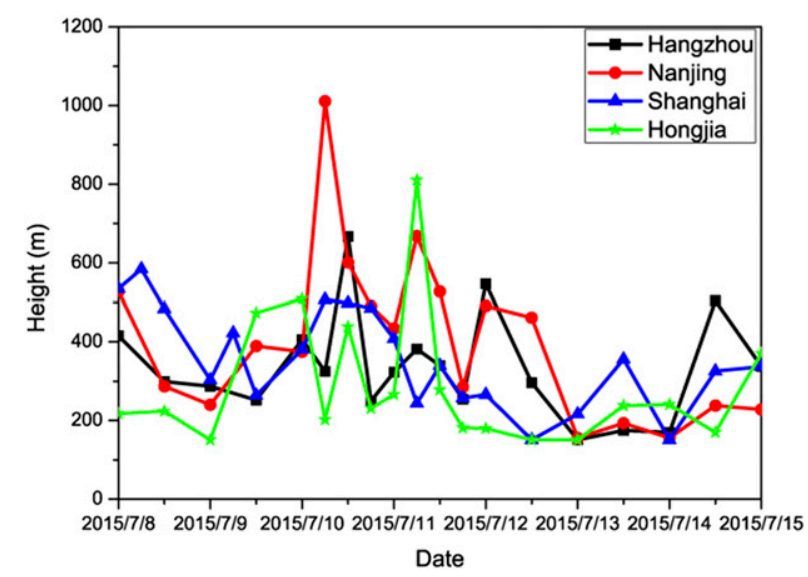

FIG. 6. The time series of the PBLH calculated from radiosonde measurements at Hangzhou (black), Nanjing (red), Shanghai (blue), and Hongjia (green) at 0000 UTC and 1200 UTC from $8 \mathrm{Jul}$ to $15 \mathrm{Jul} 2015$, using the virtual potential temperature method (VPTM).

weakly stable boundary layers, and unstable boundary layers. The mostly widely used range of $\mathrm{Ri}_{b}$ is from 0.25 to 0.5 (Zhang et al. 2011; Kepert 2012). It has also been proposed that the optimal value of $\mathrm{Ri}_{b}$ increases with the PBL and becomes increasingly unstable (Zhang et al. 2011; Kepert 2012); $\mathrm{Ri}_{b}$ values of $0.24,0.31$, and 0.39 are found to work for strongly stable layer, weakly stable layer and unstable layer conditions, respectively. In this study, the data were collected during the TC landfall period, which occurred under unstable boundary layer conditions; thus, a threshold of 0.39 is selected, and $\mathrm{Ri}_{b}$ values of 0.25 and 0.5 are also discussed.

Figure $7 \mathrm{~b}$ indicates an increasing trend in the PBLH via the VRTM when the TC makes landfall, which is different from the changing trend in the PBLH produced by the HM. This will be discussed at the end of this section. Before landfall, the PBLHs were all less than $1000 \mathrm{~m}$. Because of an earlier landfall by Chan-hom at the Hongjia station, the maximum PBLH first occurred at this station. On 9 July, the PBLH above the Hongjia station increased sharply to $997 \mathrm{~m}$ at 1200 UTC and kept growing until 11 July. The maximum PBLH at this station was $1981 \mathrm{~m}$ at 1800 UTC 10 July. Hangzhou station was the second-most influenced station by Chan-hom, and the PBLH of this station reached up to a maximum of $1490 \mathrm{~m}$ at 0600 UTC 10 July. For the Shanghai and Nanjing stations, their PBLHs both began to increase on 10 July and had peak values on 11 July. Furthermore, the PBLH at the Nanjing station was higher than those at the Shanghai and Hangzhou stations. This is also consistent with the relationship among the PBLH, turbulent diffusivity, and inertial stability. With the increase in temperature after 12 July, the PBLHs at all stations fell abruptly to less than $1000 \mathrm{~m}$.

By comparing Figs. $7 \mathrm{a}-\mathrm{c}$, we discovered that the PBLH could be impacted by the selection of the $\mathrm{Ri}_{b}$. When the threshold value was enhanced, the PBLH became bigger. As depicted in the figure, we adjusted the $\mathrm{Ri}_{b}$ from 0.25 to 0.39 and then 0.5 , and the PBLH only improved slightly before and after the TC landfall. For example, at 1200 UTC on July 8, the PBLHs over the Shanghai station were 450, 568, and $631 \mathrm{~m}$ based on different $\mathrm{Ri}_{b c}$ values of $0.25,0.39$, and 0.5 , respectively. In addition, at 0000 UTC 15 July, the PBLHs were 337, 385 , and $395 \mathrm{~m}$, respectively. However, within the time period of the Chan-hom landfall, the sensitivity test suggested a more obvious increase in the PBLH. At the Hangzhou station, the PBLH increased from 1386 to $1645 \mathrm{~m}$ and then $1835 \mathrm{~m}$ with an increase in $\mathrm{Ri}_{b c}$ at 1200 UTC 10 July. In addition, the same situation was also found at 1800 UTC 10 July at the Hongjia station (e.g., the PBLH increased from 1100 to $1981 \mathrm{~m}$ and then $2216 \mathrm{~m}$ ). In conclusion, under typical weather conditions, the increase in $\mathrm{Ri}_{b c}$ increased the PBLH within several decameters, while under extremely unstable conditions, the increase in $\mathrm{Ri}_{b c}$ could cause deviations of several hundred meters. This apparent feature illustrates that a qualifying and reliable value of $\mathrm{Ri}_{b c}$ is
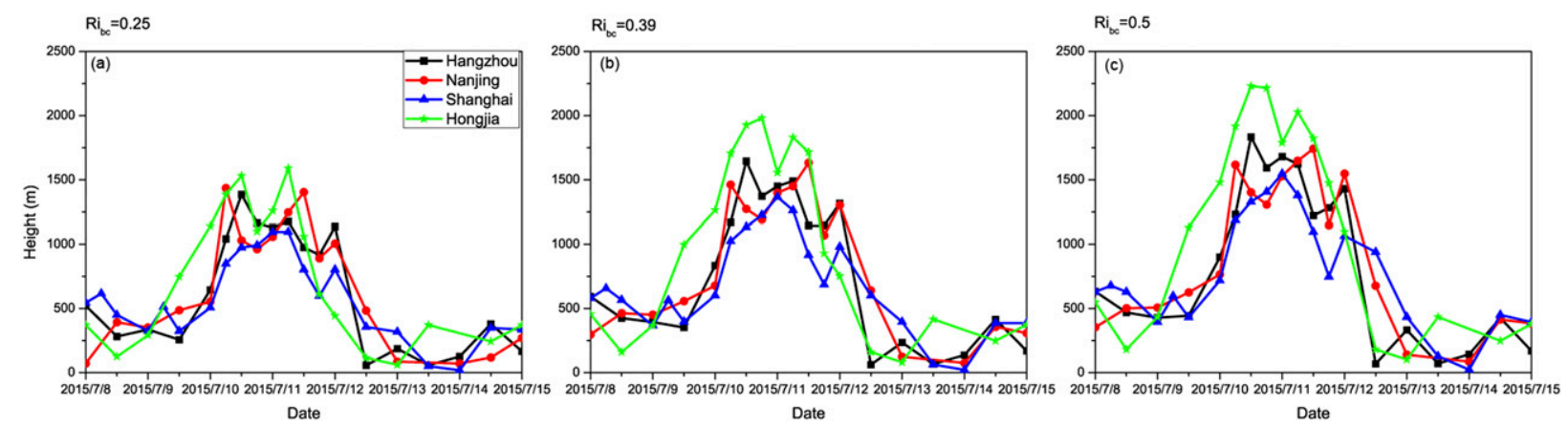

FIG. 7. The PBLH calculated by the bulk Richardson number method (BRNM) for different threshold values: (a) $\mathrm{Ri}_{b c}=0.25,(\mathrm{~b}) \mathrm{Ri} \mathrm{i}_{b c}=$ 0.39 , and (c) $\mathrm{Ri}_{b c}=0.5$. 


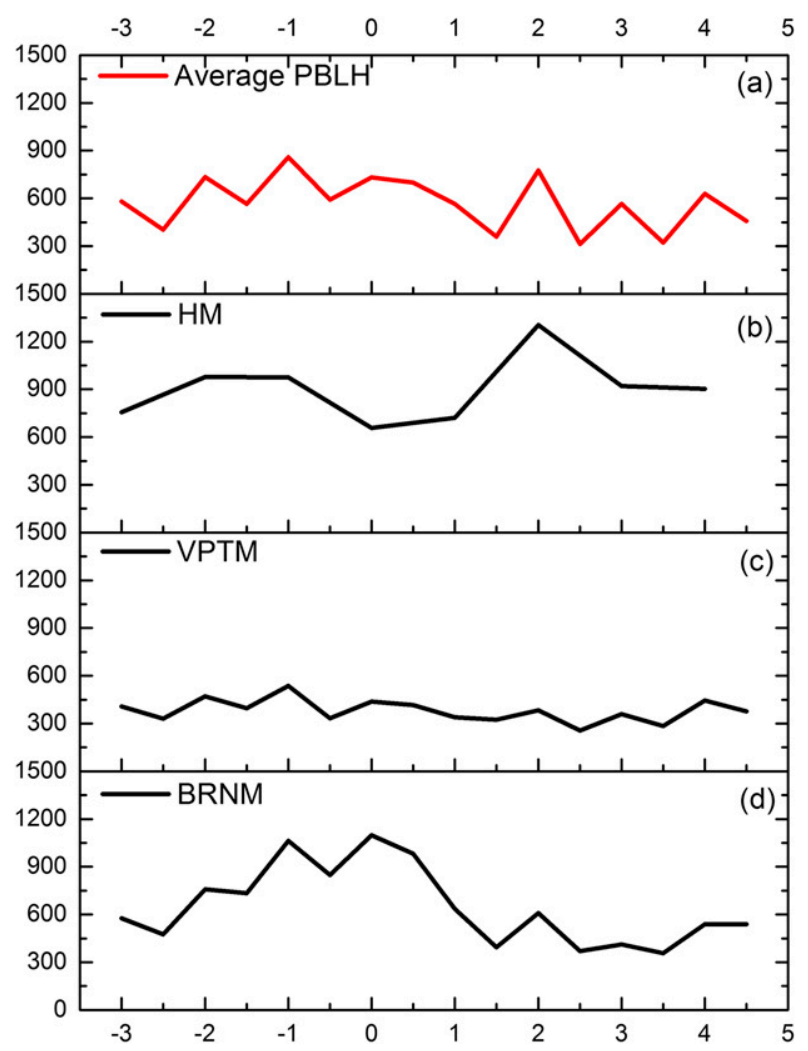

FIG. 8. The average PBLH calculated by (a) all methods, (b) HM, (c) VPTM, and (d) BRNM $\left(\mathrm{Ri}_{b c}=0.39\right)$. The $x$ axis indicates the day before (negative) and after (positive) TC landfall.

essential in the determination of the PBLH, especially under unstable TC conditions. When the thermal stratification structures occur in the TC, it will affect the estimate of the TCBL height from the HM, PTGM, and VPTM. Figure 8 gives the TCBL height calculated from the different methods. As we can see, the TCBL height from the BRNM is larger than other thermal-dynamic results on $11 \mathrm{July}$, which is consistent with the previous results (Zhang et al. 2011).

The characteristics of the variation trends were similar to those of a single TC. For the HM, the average height decreased slightly to $656.87 \mathrm{~m}$ when the TC made landfall and soon increased during the following day. The minimum PBLH was slightly higher than that of the single TC Chan-hom. For the VPTM, the average height fluctuated near $400 \mathrm{~m}$ throughout the entire period. On the day of TC landfall, no obvious PBLH variations were found. However, the PBLH from the BRNM increased quickly on the day of TC landfall. The maximum PBLH could reach up to $858.45 \mathrm{~m}$. The average PBLH for both the HM and BRNM was approximately $600 \mathrm{~m}$. From the average PBLH produced by the three methods, there were obvious fluctuations during the day and night periods. The PBLH during the daytime was approximately $200-300 \mathrm{~m}$ higher than that at night. When the TC made landfall, the PBLH elevated slightly.

It can be seen from Fig. 9 that for the HM, VPTM, and the BRNM, many aberrant points were judged, especially in the BRNM. However, the upward tendencies of the PBLH for the BRNM and VPTM were obvious. In Fig. 9d, the PBLHs were similar before and after TC landfall. The PBLH range was between 100 and $1500 \mathrm{~m}$, and the 25th and 75 th percentiles were from approximately 300 to $1000 \mathrm{~m}$, except for two days after TC landfall. The maximum heights during this time were all above $1000 \mathrm{~m}$, and the minimum heights were below $250 \mathrm{~m}$. In addition, the general tendency integrated by all methods indicated that the PBLH would increase $200-300 \mathrm{~m}$ when the TC made landfall.

\section{c. A case study}

We selected the results of the Shanghai station as the case study, and the PTGM is introduced. Figure 10 illustrates that a disagreement exists among the four methods, and they generally yielded heights that differed by several hundred meters. Detailed heights via the four methods are shown in Table 3.

In most cases, the VPTM produced the lowest heights compared to those from the other three methods. If there was no special weather process, the results of the BRNM and VPTM were similar. For example, on 8 July, the PBL heights from the BRNM and VPTM methods were 581.00 and $534 \mathrm{~m}$ then 387.00 and $337 \mathrm{~m}$ on $15 \mathrm{July}$, respectively. On 10 and 11 July, the differences among the four methods became more obvious.

For the HM, the definition considers the PBL to be a thermodynamical layer, where the potential temperature and specific humidity are nearly invariant with height. But the top of this layer is thus a little different distinct from the top of the boundary layer in tropical cyclones. Based on the measurements of temperature, potential temperature, virtual potential temperature, relative humidity, specific humidity, and refractivity profiles, Seidel et al. (2010) compared the PBLHs from seven typical methods. It was found that the PBLHs calculated by the virtual potential temperature were always lower than and poorly correlated with the PBLHs from other methods. And this is to be expected since there is a layer of marked thermal stability near the top of the inflow layer in a TC and thus the thermodynamic definition of the TCBL height is usually about half of that generated a dynamical definition. For the BRNM, the turbulent wind shear effect on the PBL is relatively high and thus cannot be neglected, which is classified as the dynamic boundary layer. In addition, the TC PBL could be affected by storm motion and the topography of the coastal region during landfall. It 

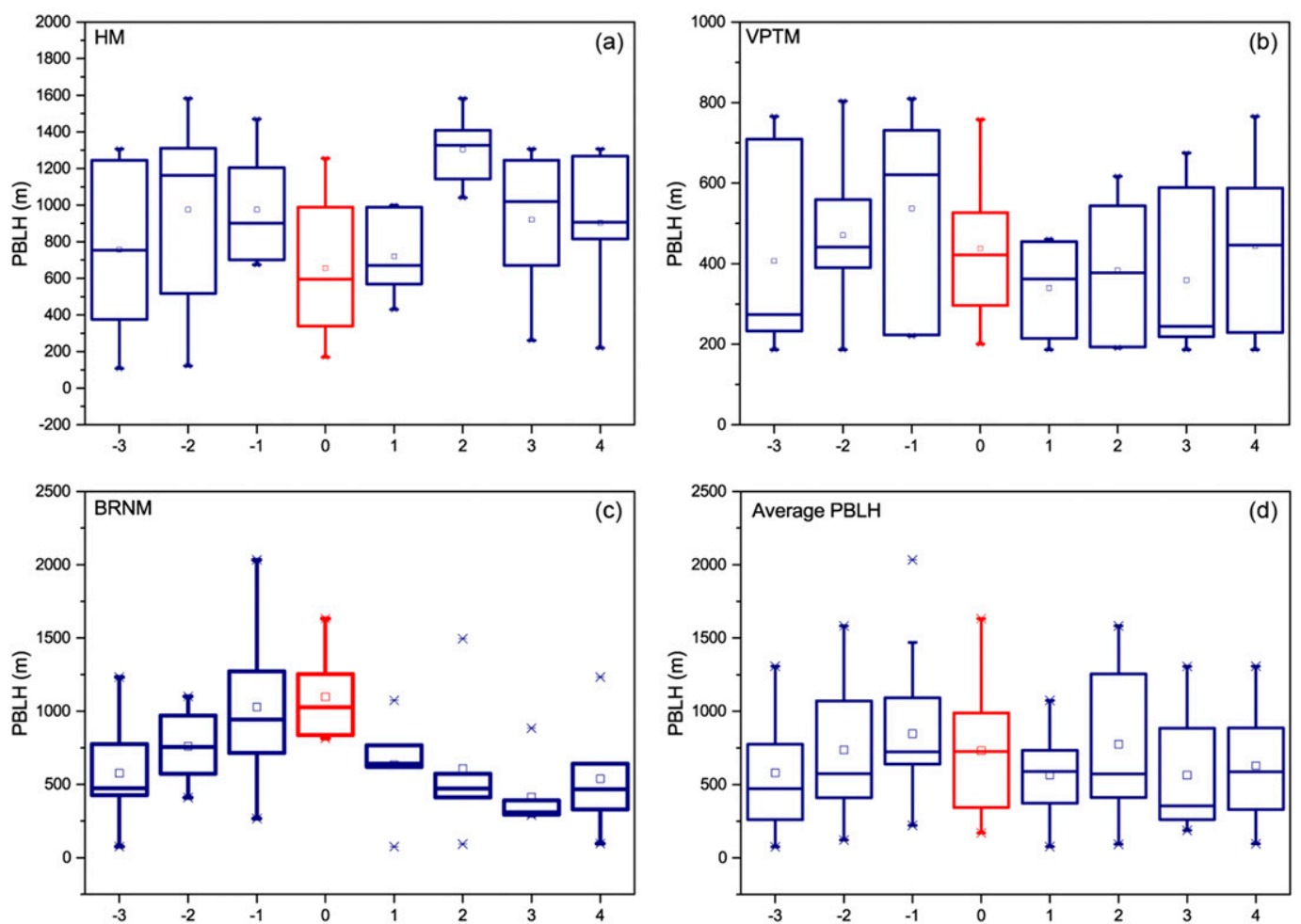

FIG. 9. The box-and-whisker plot for the PBLH calculated via four methods. The lines represent the values of the minimum and maximum heights and the mean 25th and 75 th percentiles. The red boxes and lines represent the day of TC landfall. The $x$ axis indicates the day before (negative) and after (positive) TC landfall.

has been confirmed by previous observations that the maximum winds should always be to the frontright quadrant of the storm motion vector (Matyas 2010). Therefore, the PBLH calculated by the BRNM usually shows an upward tendency during the TC landfall, and when the station lies in the front-right quadrant of forward motion this effect could become more obvious. Therefore, the landfall of a TC makes the dynamic process more easily stand out compared to the dynamic process under ordinary atmospheric conditions when the thermodynamic vertical mixing process plays a leading role. Under continuously hightemperature weather conditions, the mixing layer actively develops.

As Kepert et al. (2016) mentioned, the top of the tropical cyclone boundary layer may be diagnosed by 1 ) the top of the layer of strong frictional inflow and/or 2) the top of the "well mixed" layer based on a constant of potential temperature. However, the observations show that these two definitions may give different results in practice, with the inflow layer being roughly twice the depth of the layer of nearly constant potential temperature (Zhang et al. 2011). The results suggest that using the traditional critical Richardson number method to determine the boundary layer height may not accurately reproduce the height scale of the hurricane boundary layer. Kepert et al. (2016) showed that the top of the inflow layer is a better proxy for the top of the boundary layer but it is not without limitations. The different height scales reveal the complexity of the hurricane boundary layer structure. Because of the adiabatic effects and horizontal advection, the vertical distribution of temperature is strongly influenced by moist processes (Kepert et al. 2016). The increase of the water vapor could lead to the increases in temperature and the thermodynamic became more obvious.

To our best knowledge, the thermal structure of the TCBL is quite complex. To illustrate the effect of each layer, the temperature and water vapor profiles before (10 July), during (11 July), and after (12 July) the landfall of TC Chan-hom (2015) were also presented here from AIRS data (see Fig. 11). On the date of 11 July 2015, the landfall of the TC brought a large amount of the water vapor to the land and made the temperature in the lower troposphere increase. However, because of lack of the observation data, the characteristics are not so obvious.

Accordingly, each method is governed by different process in the PBL, and some of them are not directly connected to what we usually call boundary layer dynamics. 

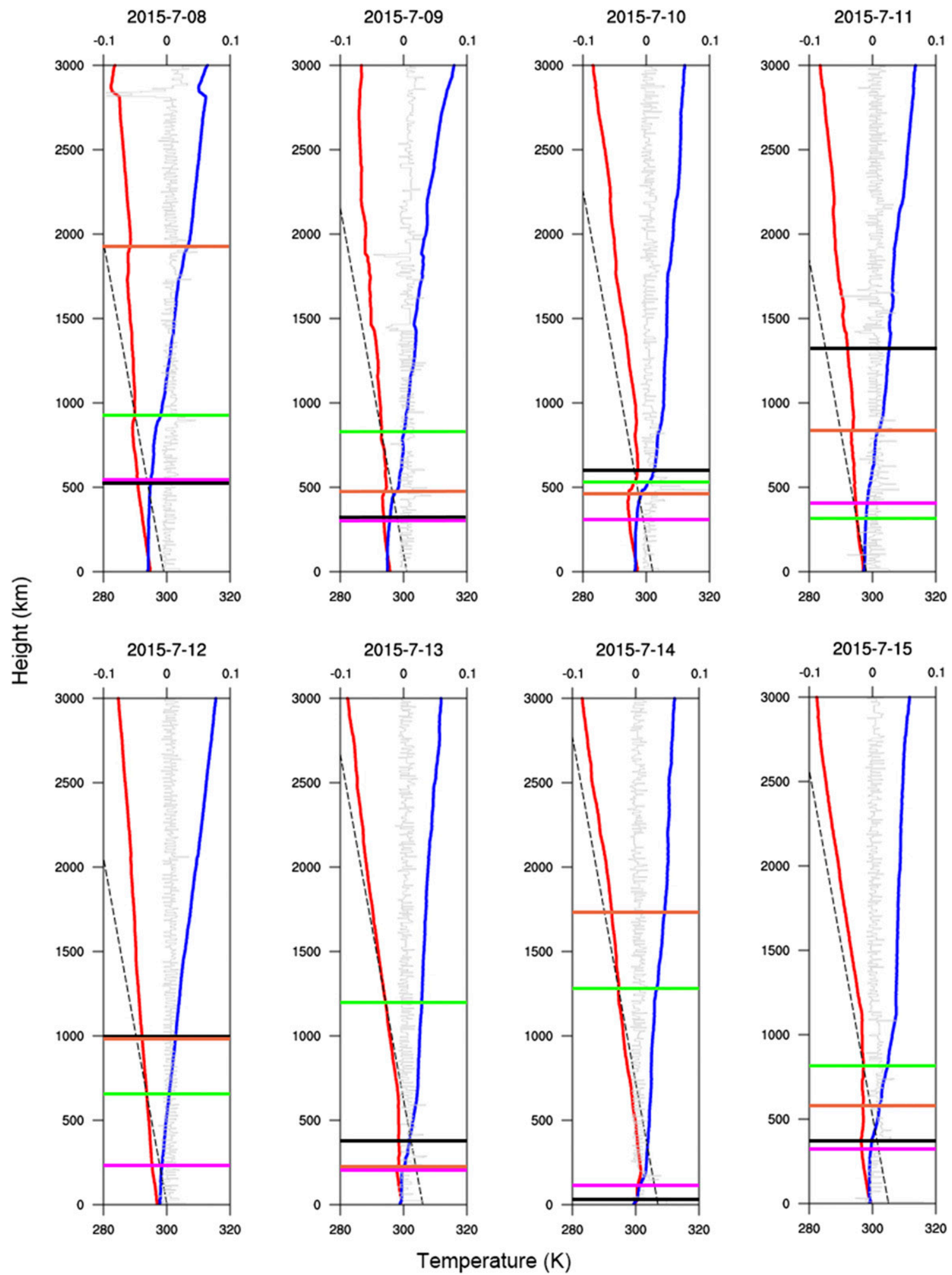

FIG. 10. Utilizing four methods (HM, VPTM, PTGM, and BRNM) to calculate the PBLH at Shanghai station at 0000 UTC from 8 to 15 Jul. The red line represents the profiles for temperature. The blue line represents the profiles for potential temperature. The black dotted line represents the dry adiabatic curve starting from the maximum surface temperature. The gray line represents the gradient of potential temperature. The PBLHs from the different methods are labeled by horizontal lines in different colors: black lines for BRNM, pink lines for VPTM, orange lines for PTGM, and green lines for HM. 
TABLE 3. The PBLH (m) calculated by the HM, BRNM, VPTM, and PTGM for the Shanghai station from 8 to $15 \mathrm{Jul}$ at $0000 \mathrm{UTC}$.

\begin{tabular}{lrrrr}
\hline \hline & HM & BRNM & VPTM & PTGM \\
\hline 8 Jul & 938.38 & 581.00 & 534.00 & 1890.00 \\
$9 \mathrm{Jul}$ & 815.43 & 367.00 & 303.00 & 481.00 \\
$10 \mathrm{Jul}$ & 544.80 & 602.00 & 381.00 & 484.00 \\
$11 \mathrm{Jul}$ & 282.64 & 1367.00 & 408.00 & 832.00 \\
$12 \mathrm{Jul}$ & 651.49 & 982.00 & 266.00 & 995.00 \\
$13 \mathrm{Jul}$ & 1225.26 & 396.00 & 216.00 & 221.00 \\
$14 \mathrm{Jul}$ & 1282.71 & 122.00 & 151.00 & 1734.00 \\
$15 \mathrm{Jul}$ & 815.42 & 387.00 & 337.00 & 606.00 \\
\hline
\end{tabular}

Depending on the different circumstances and focuses, an appropriate method should be selected. When a TC makes landfall in East China, we should not only emphasize the temperature but the momentum and humidity as well. The BRNM is more suitable for PBL estimations because of the strong dynamic process during TC landfall compared to the HM.

The TCBL height should be determined primarily by dynamical considerations, which is different than the PBL in general. The multiple types of observations revealed the different aspects of the PBL characteristics leading to inevitable PBL differences. In addition, the multiple types of observations revealed the different aspects of the PBL characteristics leading to inevitable
PBL differences. Even for a single data source, the different methods tend to estimate the PBLH with a wide range of results.

According to the calculation of the typhoon center path (Fig. 1), it can be seen that on 11 July 2015, Hongjia station is the closest to the typhoon center and shows the highest wind speed as seen in Fig. 3. The numerical simulations by Huang (2018) also indicate that the winds show strongest around the Hongjia station, which is consistent with our observation. In addition, the typhoon track shows a dramatic change from the land to the eastern sea after landfall. Meanwhile, in the coastal area around the typhoon's landfall, the local topography shows relatively higher elevations at Hongjia surrounding than the one at Shanghai surrounding (Shi and Huang 2015). Therefore, the wind speeds at the radiosonde stations are affected by their distances from the typhoon center, local topography, and the typhoon track, which subsequently affect the PBL height calculated from the bulk Richardson number method. As demonstrated in Fig. 7, the PBL height is highest at Hongjia station during the typhoon landfall on 11 July because of its strongest winds. On the other hand, previous observations indicate that the maximum winds are located in the front-right quadrant of the storm motion vector (Matyas 2010). Therefore, the PBL height calculated by the
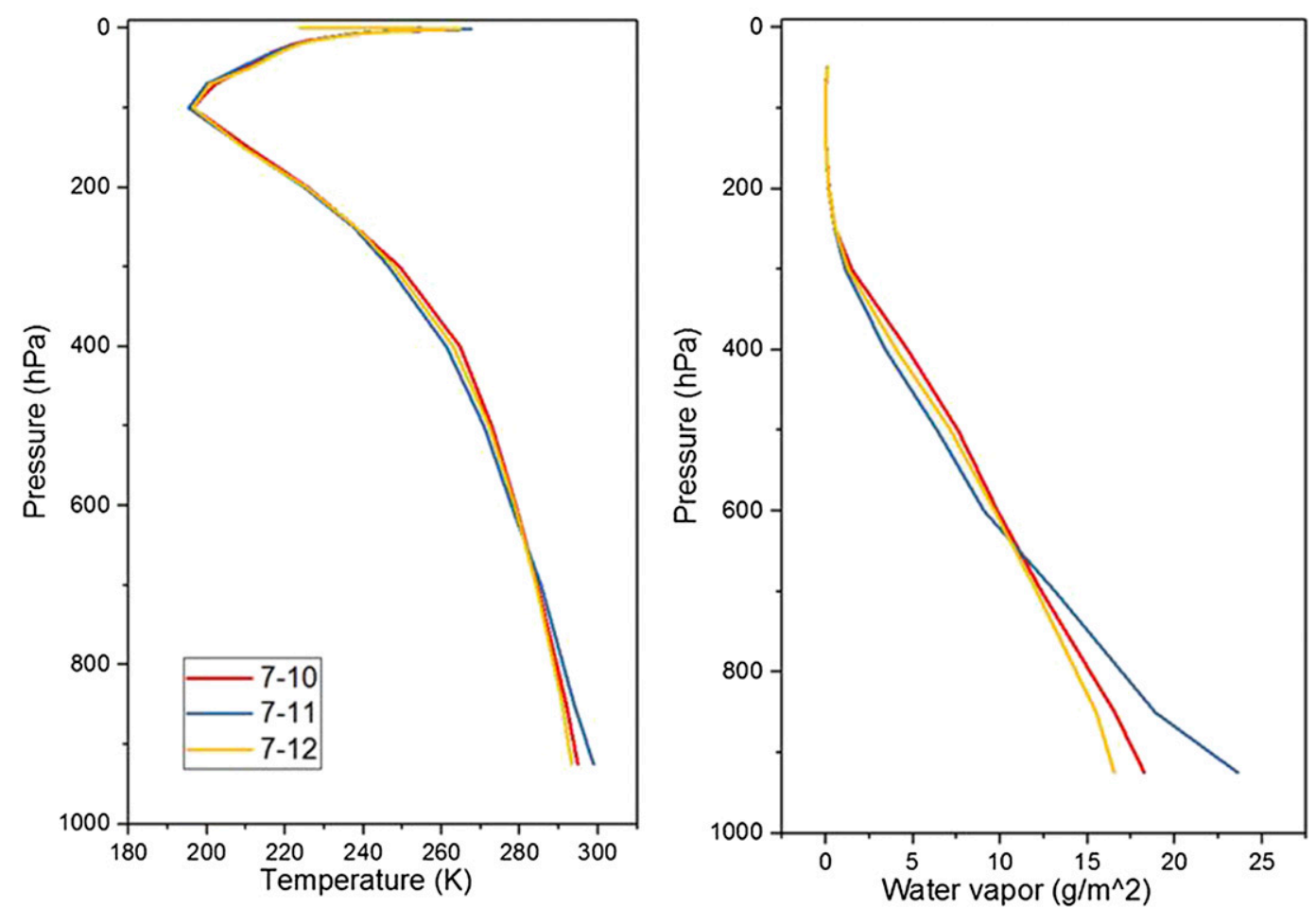

FIG. 11. The temperature and water vapor profile from the AIRS instrument on 10-12 Jul 2015 at the landing point of TC Chan-hom. 
BRNM usually shows an obvious upward tendency during the TC landfall. Therefore, the landfall of a TC makes the dynamic process more easily stand out compared to that under ordinary atmospheric conditions when the thermodynamic vertical mixing process plays a leading role.

\section{Conclusions}

The general PBL characteristics during the TC landfall period have been discussed in this paper using L-band high-spatial-resolution radiosonde datasets from the Shanghai, Nanjing, Hangzhou, and Hongjia stations from 8 to 15 July 2015 . We analyzed the variations in temperature, relative humidity and wind speed when TC Chan-hom made landfall and the PBLH via 4 different methods. The temperatures all decreased 3$4 \mathrm{~K}$ on 11 and 12 July under $2000 \mathrm{~m}$ at the four stations. The landfall of Chan-hom also brought plenty of moisture, especially at the 1000-3000-m levels. The most obvious change was the sharp increase in wind speed. At the Hongjia station, the speed reached up to $30 \mathrm{~m} \mathrm{~s}^{-1}$. Nanjing was the farthest station from the TC center compared to the other three stations, and the speed also showed apparent increases. Therefore, the landfall of a TC changes the lower level of atmospheric elements and leads to transitory changes in the PBL structure.

We used several methods (HM, PTGM, BRNM, and VPTM) to calculate the PBLH from 8 to 15 July. Based on the linear model, the PBLH decreases close to the center core and the results are consistent with theory. Because of the different physical mechanisms of the four methods, their results show some discrepancies. For the $\mathrm{HM}$, the PBL height showed a significant decrease when the TC approached, which might be because only the extent of vertical mixing was considered. In other words, the HM is influenced by the ground surface temperature and thermodynamic processes. For the BRNM and VPTM, they both showed an upward tendency for the PBL height during TC landfall. Meanwhile, the PBLH was closely related to the selection of $\mathrm{Ri}_{b c}$. The unstable atmospheric structure always causes the PBLH variation to be more sensitive to increasing values of $\mathrm{Ri}_{b c}$. The importance of horizontal mixing during atmospheric dispersion and the dynamic process are emphasized in the BRNM. Therefore, it helps us understand the diversity of the results. The results of the PTGM were also compared, and they varied by several hundred meters. Overall, the different methods may depict the various characteristics of the PBLH, and they should be applied to different weather conditions selectively. In this study, we discovered that PBLH calculated by different methods was different because the different physical mechanisms of the four methods show some discrepancies. The liner theory of Kepert reflected the dynamic process in the boundary layer (Kepert and Wang 2001). We also chose another five TCs to explore the average PBLH calculated by the different methods. The results for temperature, relative humidity, and wind speed showed that more TCs would eliminate random errors caused by other weather processes. Although their average value changes were smooth in comparison to a single TC, the characteristics of the vertical meteorological elements still appeared in the mean state. The average PBLH variation tendency from each method was similar to that for the single TC, but the diurnal variation became more obvious. When we calculated the average PBLH via all methods, the PBLH increased slightly under the influence of a TC. Overall, the PBLH exhibited large variability during the period of TC landfall, ranging from less than $250 \mathrm{~m}$ to greater than $1500 \mathrm{~m}$.

However, there were not enough high-temporalresolution observation data available; therefore, the temporal variation in the PBL cannot be explicitly characterized during the TC period. The present work provides us with the PBLHs calculated using different methods based on a radiosonde dataset, which shows great discrepancies. The influential factors for this discrepancy are worthy of more detailed studies in the future by combining a convection-permitting model with radiosonde measurements at shorter time intervals (i.e., 1- and 3-h time intervals).

Acknowledgments. This work was jointly supported by the National Science and Technology Major Project (Grant 2016YFC0203303), the National Science Foundation of Jiangsu Province (Grant BE2015151), and the National Science Foundation of China (Grants 41775026, 41075012, and 40805006). Y. Wu is supported by NOAA-CREST (Grant NA16SEC4810008). Dr. J. Guo is financially supported by the Ministry of Science and Technology of China under Grant 2017YFC1501401. In particular, the authors thank Gabriel J. Williams Jr. and the anonymous reviewers for their insightful comments and opinions on this article, which are very helpful to improve the quality of our work.

\section{REFERENCES}

Anderson, P. S., 2009: Measurement of Prandtl number as a function of Richardson number avoiding self-correlation. Bound.-Layer Meteor., 131, 345-362, https://doi.org/10.1007/ s10546-009-9376-4.

Anthes, R. A., and S. W. Chang, 1978: Response of the hurricane boundary-layer to changes of sea surface temperature in a numerical model. J. Atmos. Sci., 35, 1240-1255, https://doi.org/ 10.1175/1520-0469(1978)035<1240:ROTHBL > 2.0.CO;2 . 
Barlow, J. F., 2014: Progress in observing and modelling the urban boundary layer. Urban Climate, 10, 216-240, https://doi.org/ 10.1016/j.uclim.2014.03.011.

Bender, M. A., I. Ginis, R. Tuleya, B. Thomas, and T. Marchok, 2007: The operational GFDL coupled hurricane-ocean prediction system and a summary of its performance. Mon. Wea. Rev., 135, 3965-3989, https://doi.org/10.1175/2007MWR2032.1.

Blackwell, K. G., 2000: The evolution of Hurricane Danny (1997) at landfall: Doppler-observed eyewall replacement, vortex contraction/intensification, and low-level wind maxima. Mon. Wea. Rev., 128, 4002-4016, https://doi.org/10.1175/15200493(2000)129<4002:TEOHDA > 2.0.CO;2.

Braun, S. A., and W. K. Tao, 2000: Sensitivity of high-resolution simulations of Hurricane Bob (1991) to planetary boundary layer parameterizations. Mon. Wea. Rev., 128, 3941-3961, https:// doi.org/10.1175/1520-0493(2000)129<3941:SOHRSO >2.0.CO;2.

Cai, N. H., X. Xu, L. L. Song, L. N. Bai, J. Ming, and Y. Wang, 2014: Dynamic impact of the vertical shear of gradient wind on the tropical cyclone boundary layer wind field. Acta Meteor. Sin., 28, 127-138, https://doi.org/10.1007/s13351-014-3058-y.

Casasanta, G., I. Pietroni, I. Petenko, and S. Argentini, 2014: Erratum to: Observed and modelled convective mixing-layer height at Dome C, Antarctica. Bound.-Layer Meteor., 153, 163-164, https:// doi.org/10.1007/s10546-014-9951-1.

Chahine, M. T., and Coauthors, 2006: AIRS: improving weather forecasting and providing new data on greenhouse gases. Bull. Amer. Meteor. Soc., 87, 911-926, https://doi.org/10.1175/ BAMS-87-7-911.

Chen, L., H. Luo, Y. Duan, and H. Yu, 2004: An overview on tropical cyclone and tropical meteorology research progress. Adv. Atmos. Sci., 21, 505, https://doi.org/10.1007/BF02915577.

Dai, C., Q. Wang, J. A. Kalogiros, D. H. Lenschow, Z. Gao, and M. Zhou, 2014: Determining boundary-layer height from aircraft measurements. Bound.-Layer Meteor., 152, 277-302, https://doi.org/10.1007/s10546-014-9929-z.

Davies, F., D. R. Middleton, and K. E. Bozier, 2007: Urban air pollution modelling and measurements of boundary layer height. Atmos. Environ., 41, 4040-4049, https://doi.org/10.1016/ j.atmosenv.2007.01.015.

Eliassen, A., and M. Lystad, 1977: The Ekman layer of a circular vortex A numerical and theoretical study. Geophys. Norv., 31, 1-16.

Flamant, C., J. Pelon, P. H. Flamant, and P. Durand, 1997: Lidar determination of the entrainment zone thickness at the top of the unstable marine atmospheric boundary layer. Bound.-Layer Meteor., 83, 247-284, https://doi.org/10.1023/ A:1000258318944.

Granados-Munoz, M. J., F. Navas-Guzman, J. A. Bravo-Aranda, J. L. Guerrero-Rascado, H. Lyamani, J. Fernandez-Galvez, and L. Alados-Arboledas, 2012: Automatic determination of the planetary boundary layer height using lidar: One-year analysis over southeastern Spain. J. Geophys. Res., 117, D18208, https://doi.org/10.1029/2012JD017524.

Guo, J. P., and Coauthors, 2016: The climatology of planetary boundary layer height in China derived from radiosonde and reanalysis data. Atmos. Chem. Phys., 16, 13 309-13 319, https:// doi.org/10.5194/acp-16-13309-2016.

Hanna, S. R., 1969: The thickness of the planetary boundary layer. Atmos. Environ., 3, 519-536, https://doi.org/10.1016/00046981(69)90042-0.

Holzworth, G. C., 1964: Estimates of mean maximum mixing depths in the contiguous United States. Mon. Wea. Rev., 92, 235-242, https://doi.org/10.1175/1520-0493(1964)092<0235: EOMMMD $>2.3 . \mathrm{CO} ; 2$.
Howard, J. R., A. L. Doggett, R. E. Peterson, P. G. Black, J. L. Schroeder, D. A. Smith, and J. P. Dunyak, 2004: Transition in onshore hurricane boundary layer winds during the landfall of Hurricane Lili (2002). 26th Conf. on Hurricanes and Tropical Meteorology, Miami, FL, Amer. Meteor. Soc., 13D.3, https:// ams.confex.com/ams/pdfpapers/75450.pdf.

Hu, X. M., J. W. Nielsen-Gammon, and F. Q. Zhang, 2010: Evaluation of three planetary boundary layer schemes in the WRF Model. J. Appl. Meteor. Climatol., 49, 1831-1844, https:// doi.org/10.1175/2010JAMC2432.1.

Huang, M., Y. Wang, W. Lou, and S. Cao, 2018: Multi-scale simulation of time-varying wind fields for Hangzhou Jiubao Bridge during Typhoon Chan-hom. J. Wind Eng. Ind. Aerodyn., 179, 419-437, https://doi.org/10.1016/j.jweia.2018.06.020.

Kaimal, J. C., and J. J. Finnigan, 1995: Atmospheric boundary layer flows: Their structure and measurement. Bound.-Layer Meteor., 72, 213-214, https://doi.org/10.1007/BF00712396.

Kepert, J. D., 2001: The dynamics of boundary layer jets within the tropical cyclone core. Part I: Linear theory. J. Atmos. Sci., 58, 2469-2484, https://doi.org/10.1175/1520-0469(2001)058<2469: TDOBLJ $>2.0 . \mathrm{CO} ; 2$.

2002: The wind-field structure of the tropical cyclone boundary layer. Ph.D. thesis, Dept. of Mathematics and Statistics, Monash University, 350 pp. [Available from Dept. of Mathematics and Statistics, Monash University, VIC 3800, Australia.]

_ 2012: Choosing a boundary layer parameterization for tropical cyclone modeling. Mon. Wea. Rev., 140, 1427-1445, https:// doi.org/10.1175/MWR-D-11-00217.1.

, and Y. Q. Wang, 2001: The dynamics of boundary layer jets within the tropical cyclone core. Part II: Nonlinear enhancement. J. Atmos. Sci., 58, 2485-2501, https://doi.org/10.1175/ 1520-0469(2001)058<2485:TDOBLJ $>2.0$. CO 2 .

- J. Schwendike, and H. Ramsay, 2016: Why is the tropical cyclone boundary layer not "well mixed"? J. Atmos. Sci., 73, 957-973, https://doi.org/10.1175/JAS-D-15-0216.1.

Leventidou, E., P. Zanis, D. Balis, E. Giannakaki, I. Pytharoulis, and V. Amiridis, 2013: Factors affecting the comparisons of planetary boundary layer height retrievals from CALIPSO, ECMWF and radiosondes over Thessaloniki, Greece. Atmos. Environ., 74, 360366, https://doi.org/10.1016/j.atmosenv.2013.04.007.

Li, Z., and Coauthors, 2017: Aerosol and boundary-layer interactions and impact on air quality. Natl. Sci. Rev., 4, 810-833, https://doi.org/10.1093/nsr/nwx117.

Liang, J., L. G. Wu, G. J. Gu, and Q. Y. Liu, 2016: Rapid weakening of Typhoon Chan-Hom (2015) in a monsoon gyre. J. Geophys. Res. Atmos., 121, 9508-9520, https://doi.org/10.1002/2016JD025214.

Matyas, C. J., 2010: Locating convection in landfalling tropical cyclones: A Gis-based analysis of radar reflectivities and comparison to lightning-based observations. Phys. Geogr., 31, 385-406, https://doi.org/10.2747/0272-3646.31.5.385.

Ming, J., J. A. Zhang, R. F. Rogers, F. D. Marks, Y. Wang, and N. H. Cai, 2014: Multiplatform observations of boundary layer structure in the outer rainbands of landfalling typhoons. J. Geophys. Res. Atmos., 119, 7799-7814, https://doi.org/10.1002/ 2014JD021637.

Moss, M. S., and F. J. Merceret, 1976: Note on several low-layer features of Hurricane Eloise (1975). Mon. Wea. Rev., 104, 967-971, https://doi.org/10.1175/1520-0493(1976)104<0967: ANOSLL $>2.0 . \mathrm{CO} ; 2$.

Nieuwstadt, F. T. M., 2005: The atmospheric boundary layer. Environmental Stratified Flows, V. Armenio and S. Sarkar, Eds., CISM Courses and Lectures, Vol. 479, Springer, 179-232. 
Noh, Y., W. G. Cheon, S. Y. Hong, and S. Raasch, 2003: Improvement of the K-profile model for the planetary boundary layer based on large eddy simulation data. Bound.-Layer Meteor., 107, 401-427, https://doi.org/10.1023/A:1022146015946.

Oke, T. R., 2002: Boundary Layer Climates. 2nd ed. Taylor \& Francis, 464 pp.

Pal, S., 2014: Monitoring depth of shallow atmospheric boundary layer to complement LiDAR measurements affected by partial overlap. Remote Sens., 6, 8468-8493, https://doi.org/ 10.3390/rs6098468.

Powell, M. D., 1987: Changes in the low-level kinematic and thermodynamic structure of Hurricane Alicia (1983) at landfall. Mon. Wea. Rev., 115, 75-99, https://doi.org/10.1175/15200493(1987)115<0075:CITLLK > 2.0.CO;2.

_ 1990: Boundary-layer structure and dynamics in outer hurricane rainbands. Part I: Mesoscale rainfall and kinematic structure. Mon. Wea. Rev., 118, 891-917, https://doi.org/ 10.1175/1520-0493(1990)118<0891:BLSADI > 2.0.CO;2.

Rao, D. V. B., and D. H. Prasad, 2007: Sensitivity of tropical cyclone intensification to boundary layer and convective processes. Nat. Hazards, 41, 429-445, https://doi.org/10.1007/ s11069-006-9052-7.

Rayhun, K. Z., D. A. Quadir, M. A. Mannan Chowdhury, M. N. Ahasan, and M. S. Haque, 2015: Simulation of structure, track and landfall of Tropical Cyclone Bijli using WRF-ARW Model. J. Bangladesh Acad. Sci., 39, 157-167, https://doi.org/ 10.3329/jbas.v39i2.25949.

Sateesh, M., C. V. Srinivas, and P. V. S. Raju, 2017: Numerical simulation of tropical cyclone thane: Role of boundary layer and surface drag parameterization schemes. Nat. Hazards, 89, 1255-1271, https://doi.org/10.1007/s11069-017-3020-2.

Schneider, R., and G. M. Barnes, 2005: Low-level kinematic, thermodynamic, and reflectivity fields associated with Hurricane Bonnie (1998) at landfall. Mon. Wea. Rev., 133, 32433259, https://doi.org/10.1175/MWR3027.1.

Seibert, P., F. Beyrich, S. E. Gryning, S. Joffre, A. Rasmussen, and P. Tercier, 2000: Review and inter-comparison of operational methods for the determination of the mixing height. Atmos. Environ., 34, 1001-1027, https://doi.org/10.1016/S13522310(99)00349-0.

Seidel, D. J., C. O. Ao, and K. Li, 2010: Estimating climatological planetary boundary layer heights from radiosonde observations: Comparison of methods and uncertainty analysis. J. Geophys. Res., 115, D16113, https://doi.org/10.1029/2009JD013680.

Shapiro, L. J., 1983: The asymmetric boundary-layer flow under a translating hurricane. J. Atmos. Sci., 40, 1984-1998, https:// doi.org/10.1175/1520-0469(1983)040<1984:TABLFU>2.0.CO;2.

Shi, J., and J. Huang, 2015: Monitoring spatio-temporal distribution of rice planting area in the Yangtze River delta region using MODIS images. Remote Sens., 7, 8883-8905, https:// doi.org/10.3390/rs70708883.

Shin, H. H., and S. Y. Hong, 2011: Intercomparison of planetary boundary-layer parametrizations in the WRF Model for a single day from CASES-99. Bound.-Layer Meteor., 139, 261281, https://doi.org/10.1007/s10546-010-9583-z.

Smith, R. K., and S. Vogl, 2008: A simple model of the hurricane boundary layer revisited. Quart. J. Roy. Meteor. Soc., 134, 337351, https://doi.org/10.1002/qj.216.

Sorbjan, Z., 1989: Structure of the Atmospheric Boundary Layer. Prentice Hall, 317 pp.
Stull, R. B., 1988: An Introduction to Boundary Layer Meteorology. Kluwer Academic, 666 pp.

Tang, X., and Z. M. Tan, 2007: Boundary-layer wind structure in a landfalling typhoon. Proc. Third China-Korea-Japan Joint Conf. on Meteorology, Hakodate, Hokkaido, Japan, Japan GLOBEC Office, http://cstm.cnki.net/stmt/TitleBrowse/ KnowledgeNet/ZGQX200711014222?db=STMI8515.

Tuleya, R. E., 1994: Tropical storm development and decay: Sensitivity to surface boundary conditions. Mon. Wea. Rev., 122, 291-304, https://doi.org/10.1175/1520-0493(1994)122<0291: TSDADS $>2.0 . \mathrm{CO} ; 2$.

Vickery, P. J., D. Wadhera, M. D. Powell, and Y. Z. Chen, 2009: A hurricane boundary layer and wind field model for use in engineering applications. J. Appl. Meteor. Climatol., 48, 381-405, https://doi.org/10.1175/2008JAMC1841.1.

Vogelezang, D. H. P., and A. A. M. Holtslag, 1996: Evaluation and model impacts of alternative boundary-layer height formulations. Bound.-Layer Meteor., 81, 245-269, https://doi.org/ 10.1007/BF02430331.

Wang, Y., and C. C. Wu, 2004: Current understanding of tropical cyclone structure and intensity changes-A review. Meteor. Atmos. Phys., 87, 257-278, https://doi.org/10.1007/s00703-0030055-6.

Williams, G. J., 2015: The effects of vortex structure and vortex translation on the tropical cyclone boundary layer wind field. J. Adv. Model. Earth Syst., 7, 188-214, https://doi.org/10.1002/ 2013MS000299.

—, R. K. Taft, B. D. McNoldy, and W. H. Schubert, 2013: Shocklike structures in the tropical cyclone boundary layer. J. $A d v$. Model. Earth Syst., 5, 338-353, https://doi.org/10.1002/ jame.20028.

Wu, C.-C., and Y. H. Kuo, 1999: Typhoons affecting Taiwan: Current understanding and future challenges. Bull. Amer. Meteor. Soc., 80, 67-80, https://doi.org/10.1175/1520-0477(1999) $080<0067$ :TATCUA $>2.0$. CO;2.

Xu, D. M., J. Z. Min, F. F. Shen, J. M. Ban, and P. Chen, 2016: Assimilation of MWHS radiance data from the FY-3B satellite with the WRF Hybrid-3DVAR system for the forecasting of binary typhoons. J. Adv. Model. Earth Syst., 8, 1014-1028, https://doi.org/10.1002/2016MS000674.

Zhang, J. A., R. F. Rogers, D. S. Nolan, and F. D. Marks, 2011: On the characteristic height scales of the hurricane boundary layer. Mon. Wea. Rev., 139, 2523-2535, https://doi.org/10.1175/ MWR-D-10-05017.1.

Zhang, W., J. Guo, Y. Miao, H. Liu, Z. Li, and P. Zhai, 2016: Planetary boundary layer height from CALIOP compared to radiosonde over China. Atmos. Chem. Phys., 16, 9951-9963, https://doi.org/10.5194/acp-16-9951-2016.

_ ary layer with different thermodynamic stability in China: A radiosonde perspective. J. Climate, 31, 1451-1465, https:// doi.org/10.1175/JCLI-D-17-0231.1.

Zhang, Y., and Coauthors, 2018: Climatology of cloud-base height from long-term radiosonde measurements in China. $A d v$. Atmos. Sci., 35, 158-168, https://doi.org/10.1007/s00376-0177096-0.

Zilitinkevich, S., and A. Baklanov, 2002: Calculation of the height of the stable boundary layer in practical applications. Bound. Layer Meteor., 105, 389-409, https://doi.org/10.1023/A: 1020376832738 